\title{
De novo mRNA synthesis is required for both consolidation and reconsolidation of fear memories in the amygdala
}

\author{
Sevil Duvarci, ${ }^{1,4}$ Karim Nader, ${ }^{2}$ and Joseph E. LeDoux ${ }^{3}$ \\ ${ }^{1}$ Center for Molecular and Behavioral Neuroscience, Rutgers, The State University of New Jersey, Newark, New Jersey 07102, \\ USA; ${ }^{2}$ Department of Psychology, McGill University, Montreal, Quebec H3A 1B1, Canada; ${ }^{3}$ W.M. Keck Foundation Laboratory \\ of Neurobiology, Center for Neural Science, New York University, New York, New York 10003, USA
}

\begin{abstract}
Memory consolidation is the process by which newly learned information is stabilized into long-term memory (LTM). Considerable evidence indicates that retrieval of a consolidated memory returns it to a labile state that requires it to be restabilized. Consolidation of new fear memories has been shown to require de novo RNA and protein synthesis in the lateral nucleus of the amygdala (LA). We have previously shown that de novo protein synthesis in the LA is required for reconsolidation of auditory fear memories. One key question is whether protein synthesis during reconsolidation depends on already existing mRNAs or on synthesis of new mRNAs in the amygdala. In the present study, we examined the effect of mRNA synthesis inhibition during consolidation and reconsolidation of auditory fear memories. We first show that intra-LA infusion of two different mRNA inhibitors dose-dependently impairs long-term memory but leaves short-term memory (STM) intact. Next, we show that intra-LA infusion of the same inhibitors dose-dependently blocks post-reactivation long-term memory (PR-LTM), whereas post-reactivation short-term memory (PR-STM) is left intact. Furthermore, the same treatment in the absence of memory reactivation has no effect. Together, these results show that both consolidation and reconsolidation of auditory fear memories require de novo mRNA synthesis and are equally sensitive to disruption of de novo mRNA synthesis in the LA.
\end{abstract}

Memory formation is a time-dependent process by which an initially labile memory is consolidated into stable long-term memory (LTM) via de novo RNA and protein synthesis (Davis and Squire 1984; Dudai and Morris 2000; McGaugh 2000; Kandel 2001). Considerable evidence indicates that retrieval (reactivation) of a consolidated memory returns it to a labile state that requires a new time-dependent process to be restabilized (reconsolidation) (Sara 2000; Nader 2003; Dudai 2004; Alberini 2005). However, relatively little is known about the cellular and molecular mechanisms involved in this process.

One important question is whether reconsolidation is an exact recapitulation of the mechanisms underlying memory consolidation. Many of the molecular mechanisms that are implicated in memory consolidation, including the activation of specific signaling cascades and protein synthesis, have also been implicated in reconsolidation (Maren 2001; Schafe et al. 2001a; Nader 2003; Rodrigues et al. 2004; Alberini 2005; Tronson and Taylor 2007). However, a number of important differences between consolidation and reconsolidation have also been reported. For instance, a double dissociation between the molecular mechanisms of consolidation and reconsolidation has been observed for contextual fear conditioning in the hippocampus (Lee et al. 2004). The requirement of transcription factor CCAAT-enhancing binding protein- $\beta(\mathrm{C} / \mathrm{EBP} \beta)$ has also been shown to be different for memory consolidation and reconsolidation (Taubenfeld et al. 2001; Tronel et al. 2005). It has also been shown that memory reconsolidation involves only some of the neurotransmitters and expression of only a

\footnotetext{
${ }^{4}$ Corresponding author.
}

E-mail duvarci@andromeda.rutgers.edu; fax (973) 353-1255.

Article is online at http://www.learnmem.org/cgi/doi/10.1101/lm.1027208. subset of immediate-early genes required during consolidation (von Hertzen and Giese 2005; Bucherelli et al. 2006), and blockade of noradrenergic receptors in the amygdala disrupts reconsolidation, but not consolidation (Debiec and LeDoux 2004).

We have previously shown that de novo protein synthesis in the LA is required for both the consolidation and reconsolidation of auditory fear memories (Schafe and LeDoux 2000; Nader et al. 2000). One key question is whether protein synthesis during reconsolidation depends on the synthesis of new mRNAs in the amygdala, similar to what has been observed for consolidation (Bailey et al. 1999; Parsons et al. 2006). Consistent with the possibility that reconsolidation requires transcription, activation of extracellular signal-regulated kinase/ mitogen activated protein kinase (ERK/MAPK) (Duvarci et al. 2005) and protein kinase A (PKA) (Tronson et al. 2006) are required for reconsolidation of auditory fear memories in the amygdala. However, a recent study has failed to show an effect of mRNA synthesis inhibition on reconsolidation of fear memories (Parsons et al. 2006). These results are at odds with several findings showing that transcription is required during reconsolidation of different types of memories in several different species (Hall et al. 2001; Kida et al. 2002; Bozon et al. 2003; Child et al. 2003; Sangha et al. 2003; Lee et al. 2004; Merlo et al. 2005; von Hertzen and Giese 2005; Boccia et al. 2007; Lubin and Sweatt 2007; Da Silva et al. 2008). Therefore, in the present study, we aimed to re-examine whether consolidation and reconsolidation of fear memories in the lateral amygdala both require de novo mRNA synthesis by using two reversible inhibitors, 5,6-dichloro$1-\beta$-D-ribofuranosylbenzimidazole (DRB) and $\alpha$-Amanitin, that work through distinct mechanisms (Chodosh et al. 1989; Gong et al. 2004) and testing their effect across a range of doses. 


\section{Results}

\section{Does inhibition of de novo mRNA synthesis in the amygdala block consolidation of auditory fear conditioning?}

First, we investigated the requirement of de novo mRNA synthesis in the lateral and basal amygdala (LBA) during consolidation of auditory fear memories. To this end, we tested the effect of two different mRNA synthesis blockers, $\alpha$-Amanitin and DRB, that have been shown to work through different mechanisms (Chodosh et al. 1989; Gong et al. 2004). Both $\alpha$-Amanitin and DRB have been shown to effectively block mRNA synthesis in vitro and in vivo (Thut and Lindell 1974; Dreyer and Hausen 1978; Chodosh et al. 1989; Ljungman et al. 1999; Gong et al. 2004; Parsons et al. 2006).

We first examined the effects of $\alpha$-Amanitin during consolidation of one-trial auditory fear conditioning (Fig. 1). We tested the dose dependence of this drug by administering four different doses. Rats were conditioned with a single pairing of tone CS and foot-shock US, followed immediately by intra-LBA infusions of $\alpha$-Amanitin ( $25 \mathrm{pg} / \mathrm{side}, 50 \mathrm{pg} / \mathrm{side}, 0.5 \mathrm{ng} / \mathrm{side}$, or $5 \mathrm{ng} / \mathrm{side}$ ) or vehicle. These doses of $\alpha$-Amanitin are consistent with what has been shown to significantly block mRNA synthesis in vivo (Thut and Lindell 1974). In order to demonstrate the specific effect of $\alpha$-Amanitin on consolidation, it is critical to show intact STM and impaired LTM. Therefore, we performed the STM test 3-4 h after conditioning and the LTM test $24 \mathrm{~h}$ after conditioning, similar to our previous studies (Nader et al. 2000; Schafe and LeDoux 2000).

A repeated-measures ANOVA comparing freezing across STM and LTM tests for all groups revealed a significant interaction between these variables $\left(F_{(4,26)}=5.08, P<0.05\right)$ (Fig. 1B).

A.

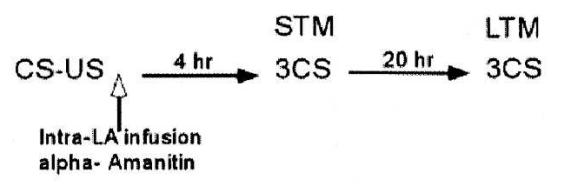

B.

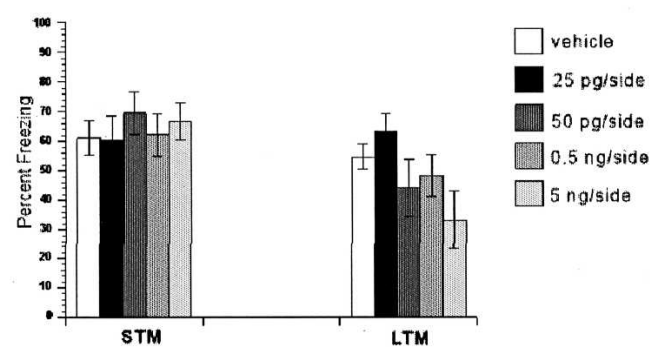

C.

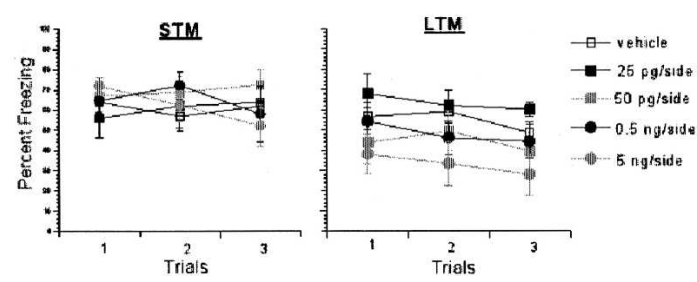

Figure 1. Inhibition of mRNA synthesis with $\alpha$-Amanitin in the LA blocked consolidation of single-trial auditory fear memories. (A) Schematic of the behavioral procedure used in the experiment. (B) DRBtreated rats showed dose-dependent impairment in the LTM test, but not the STM test. The average of three CSs is shown for the freezing scores during the STM and LTM tests. (C) The freezing scores during each CS of the STM and LTM tests are shown. Data represent group means \pm SEM.
A.

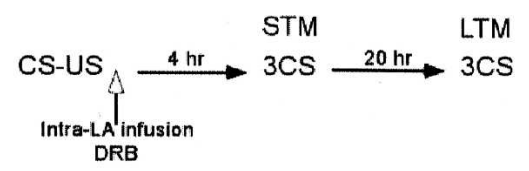

B.

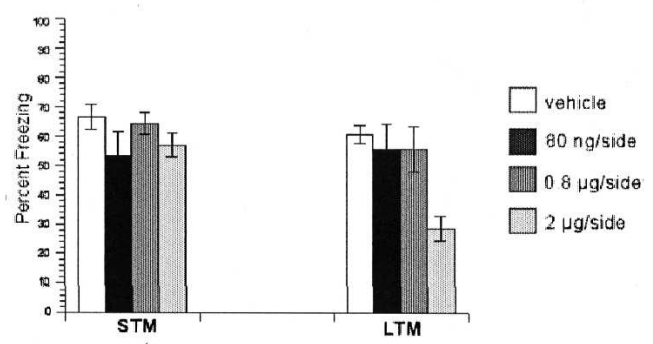

C.

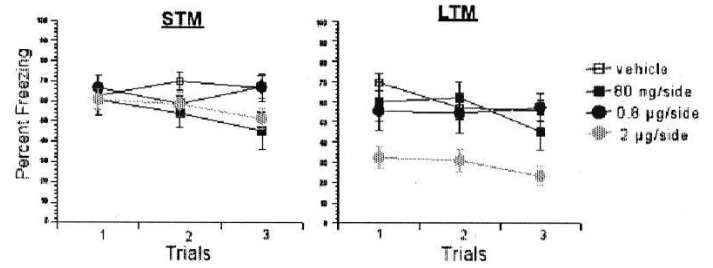

Figure 2. DRB blocked consolidation of single-trial auditory fear memories, verifying the results of $\alpha$-Amanitin. (A) Schematic of the behavioral procedure used in the experiment. $(B) \alpha$-Amanitin dosedependently impaired LTM, but not STM. The average of three CSs is shown for the freezing scores during the STM and LTM tests. (C) The freezing scores during each CS of the STM and LTM tests are shown. Data represent group means \pm SEM.

Post hoc tests revealed that all groups had similar STM scores $(P>0.05)$ (Fig. 1C). On the LTM test, the rats treated with $\alpha$ Amanitin demonstrated a dose-dependent impairment (Fig. 1C). Post hoc analyses revealed significant difference between the vehicle group and the highest dose $(5 \mathrm{ng} / \mathrm{side}) \alpha$-Amanitin group $(P<0.05)$, while there was no significant difference between the vehicle group and the other three $\alpha$-Amanitin groups $(P>0.05)$. These results suggested that LTM of auditory fear conditioning is dose-dependently impaired by $\alpha$-Amanitin. This pattern of findings, intact STM and impaired LTM, suggests that de novo mRNA synthesis in the lateral amygdala is required for the consolidation of auditory fear memories.

Although $\alpha$-Amanitin inhibits mRNA synthesis by blocking the activity of RNA polymerase II, it also inhibits synthesis of other RNAs and affects translation at high concentrations. Because the main focus of our study was on the effects of inhibiting mRNA synthesis, we used four different doses in order to find the lowest effective dose.

To further verify that the effects of $\alpha$-Amanitin on memory consolidation were due to mRNA synthesis blockade, we next used a second inhibitor of mRNA synthesis, DRB, which works through a different mechanism than that of $\alpha$-Amanitin (Fig. 2). We tested the dose-response curve of this drug by administering three different doses. Similar to $\alpha$-Amanitin experiments, rats were conditioned with a single pairing of CS-US, followed immediately by intra-LBA infusions of DRB ( $80 \mathrm{ng} / \mathrm{side}, 0.8 \mu \mathrm{g} / \mathrm{side}, 2$ $\mu \mathrm{g} / \mathrm{side}$ ) or vehicle (50\% DMSO). A repeated-measures ANOVA comparing freezing across STM and LTM tests for all groups revealed a significant interaction between these variables $\left(F_{(3,21)}=9.65, P<0.05\right)$ (Fig. $\left.2 \mathrm{~B}\right)$. Post hoc analyses demonstrated that while all groups showed similar STM scores $(P>0.05)$ (Fig. 2C), on the LTM test, the rats treated with DRB demonstrated a dose-dependent impairment (Fig. 2C). There was a significant 
A.

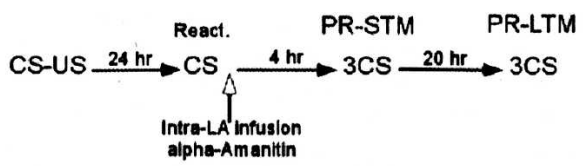

B.

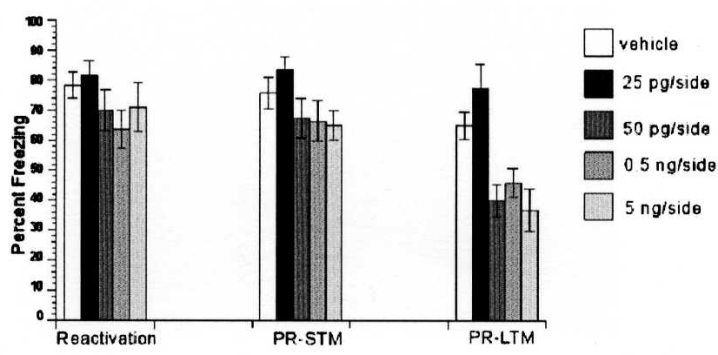

C.

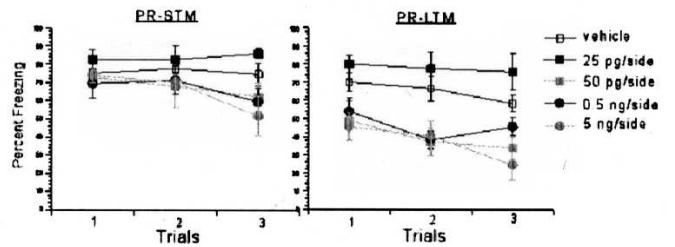

Figure 3. Blockade of mRNA synthesis with $\alpha$-Amanitin blocked reconsolidation of single-trial auditory fear memories. (A) Schematic of the behavioral procedure used in the experiment. (B) Similar to consolidation results, $\alpha$-Amanitin-treated rats showed dose-dependent impairment of PR-LTM, but not PR-STM. The average of three CSs is shown for the freezing scores during the PR-STM and PR-LTM tests. (C) The freezing scores during each CS of the PR-STM and PR-LTM tests are shown. Data represent group means \pm SEM.

difference between the control group and the highest dose $(2$ $\mu \mathrm{g} /$ side $)$ group $(P<0.05)$, while no differences existed between the control and the two low dose ( $80 \mathrm{ng} / \mathrm{side}, 0.8 \mu \mathrm{g} / \mathrm{side})$ groups $(P>0.05)$, indicating that LTM of auditory fear conditioning is dose-dependently impaired by DRB. This pattern of findings, intact STM and impaired LTM, verifies the results of the $\alpha$ Amanitin experiment on the requirement of de novo mRNA synthesis for consolidation of auditory fear memories.

Does inhibition of de novo mRNA synthesis in the amygdala block reconsolidation of auditory fear conditioning?

Next, we investigated whether de novo mRNA synthesis is required in the amygdala during reconsolidation of auditory fear memories. Similar to the consolidation experiments presented above, we investigated the role of de novo mRNA synthesis during reconsolidation of one-trial learning using the two mRNA synthesis blockers. To this end, rats were trained with a single pairing of auditory CS and foot shock US. Twenty-four hours later, they were presented with a single CS to reactivate their memory followed by intra-LBA infusions of $\alpha$-Amanitin or vehicle (Fig. 3A). The same doses ( $25 \mathrm{pg} / \mathrm{side}, 50 \mathrm{pg} / \mathrm{side}, 0.5 \mathrm{ng} /$ side, or $5 \mathrm{ng} /$ side) administered during the consolidation experiment were used to compare the dose-response curve of $\alpha$ Amanitin during consolidation and reconsolidation. During reactivation, all groups showed similar freezing scores. A one-way ANOVA revealed no significant difference between the groups $(F<1)$. A repeated-measures ANOVA comparing the effects of drug treatment over test session (post-reactivation short-term memory [PR-STM] vs. post-reactivation LTM [PR-LTM]) revealed a significant interaction between these variables $\left(F_{(4,25)}=4.61\right.$, $P<0.05$ ) (Fig. 3B). Further post hoc analyses on interaction dem- onstrated that all groups had similar PR-STM scores $(P>0.05)$ (Fig. 3C). During LTM test, there was a significant difference between the vehicle and the two $\alpha$-Amanitin groups ( $50 \mathrm{pg} / \mathrm{side}, 5$ $\mathrm{ng} /$ side), while no difference existed between the vehicle and the $25 \mathrm{pg} /$ side and $0.5 \mathrm{ng} /$ side $\alpha$-Amanitin groups (Fig. 3C). This pattern of findings, intact PR-STM and impaired PR-LTM, suggests that de novo mRNA synthesis in the LA is required for the reconsolidation of auditory fear memories.

To ensure that the behavioral effects of $\alpha$-Amanitin are contingent on memory reactivation, the same behavioral procedure was performed with the exception that the memory reactivation was omitted (Fig. 4A). If the behavioral impairment was due to blockade of reconsolidation, then without the memory reactivation, the memory should stay insensitive to $\alpha$-Amanitin's effect. To test this, the animals were exposed to the testing context for the same amount of time it took to reactivate the memory without receiving any CSs, and then received the high dose of $\alpha$ Amanitin that blocked reconsolidation in the previous experiment. Both control and drug groups showed similar levels of freezing in the PR-STM and PR-LTM tests (Fig. 4B). A repeatedmeasures ANOVA comparing drug treatment and test session revealed no significant interaction between these variables $(F<1)$. Consistent with this, post hoc tests indicated that the groups did not differ from each other on either test $(P>0.05)$. These results verified the behavioral effects of $\alpha$-Amanitin on PR-LTM and demonstrated that de novo mRNA synthesis in the LA is required for reconsolidation of auditory fear memories.

Next, we aimed to verify the effect of $\alpha$-Amanitin on reconsolidation by using the second inhibitor, DRB (Fig. 5). The same doses ( $80 \mathrm{ng} / \mathrm{side}, 0.8 \mu \mathrm{g} / \mathrm{side}, 2 \mu \mathrm{g} / \mathrm{side}$ ) of DRB administered in consolidation experiments were used. Rats were trained with a single pairing of auditory CS and foot shock US. Twenty-four hours later, they were presented with a single CS to reactivate their memory followed by intralateral amygdala infusions of DRB or the vehicle. During reactivation, all four groups showed similar freezing scores. A one-way ANOVA revealed that there was no significant difference between the groups $(F<1)$. A repeatedmeasures ANOVA comparing the effects of drug treatment over test session (PR-STM vs. PR-LTM) revealed a significant interaction between these variables $\left(F_{(3,19)}=6.03, P<0.05\right)$ (Fig. 5B).

A.

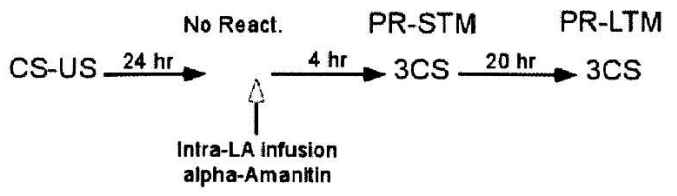

B.

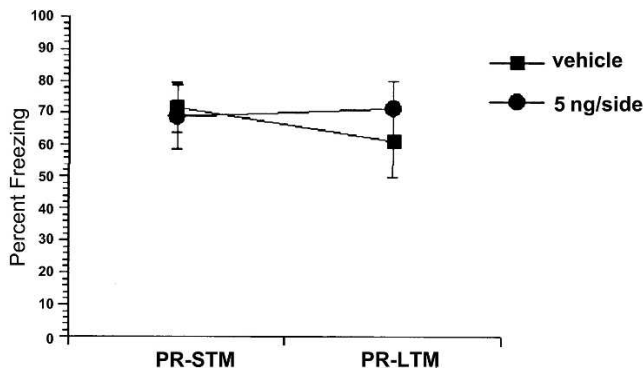

Figure 4. Effect of $\alpha$-Amanitin on reconsolidation was dependent on memory reactivation. (A) Schematic of the behavioral procedure used in the experiment. (B) Omission of reactivation resulted in lack of $\alpha$ Amanitin's effect. The $\alpha$-Amanitin-treated rats showed similar levels of freezing to vehicle rats in both the PR-STM and PR-LTM tests. The average of three CSs is shown for the freezing scores during the PR-STM and PR-LTM tests. Data represent group means \pm SEM. 
A.

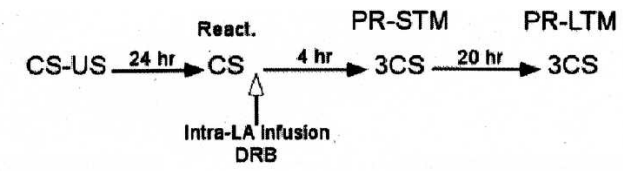

B.

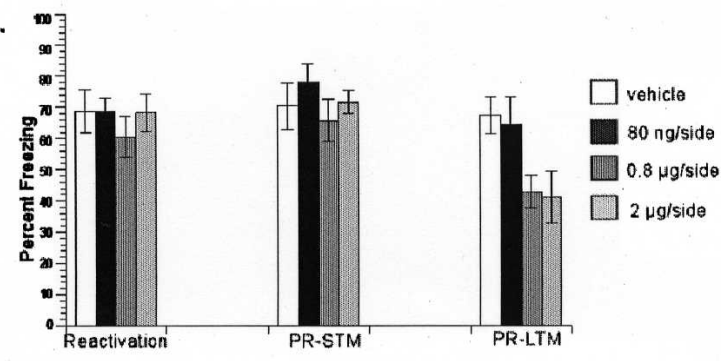

C.
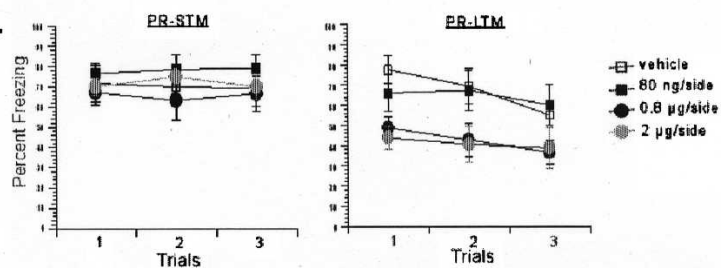

Figure 5. DRB blocked reconsolidation of single-trial auditory fear memories, verifying the effect of $\alpha$-Amanitin on reconsolidation. $(A)$ Schematic of the behavioral procedure used in the experiment. (B) DRB dosedependently impaired PR-LTM, but not PR-STM. The average of three CSs is shown for the freezing scores during the PR-STM and PR-LTM tests. (C) The freezing scores during each CS of the PR-STM and PR-LTM tests are shown. Data represent group means \pm SEM.

Further post hoc analyses on interaction showed that there was no significant difference between the groups on PR-STM scores $(P>0.05)$ (Fig. 5C). On the other hand, during the PR-LTM test, there was a significant difference between the vehicle and the two high-dose DRB groups $(0.8 \mu \mathrm{g} / \mathrm{side}, 2 \mu \mathrm{g} / \mathrm{side}$; both $P s<0.05)$, while there was no difference between the vehicle and the low-dose DRB (80 ng/side; $P>0.05$ ) groups (Fig. 5C). This pattern of findings, intact PR-STM and impaired PR-LTM, suggests that de novo mRNA synthesis in the LA is required for the reconsolidation of auditory fear memories. Similar to $\alpha$ Amanitin, the effective dose of DRB to impair reconsolidation was found to be lower than that of consolidation.

To test whether the behavioral effects of DRB are predicated on memory reactivation, we omitted reactivation (Fig. 6A). In the absence of memory reactivation, DRB had no effect. Both vehicle and DRB groups showed similar levels of freezing in the PR-STM and PR-LTM tests (Fig. 6B). A repeated-measures ANOVA comparing drug treatment and test session revealed no significant interaction between these variables $(F<1)$. The lack of DRB's effect in the absence of memory reactivation demonstrated that the effect observed is contingent on memory reactivation, and hence, the impairment is due to blockade of memory reconsolidation.

\section{Consolidation and reconsolidation are equally sensitive to disruption of de novo mRNA synthesis}

These results suggest that both consolidation and reconsolidation of fear memories require de novo mRNA synthesis in the LA. An additional important question is whether these two processes are equally sensitive to blockade of mRNA synthesis. To test this directly, we compared the effect of each dose of the two inhibitors during consolidation and reconsolidation. To this end, we
A.

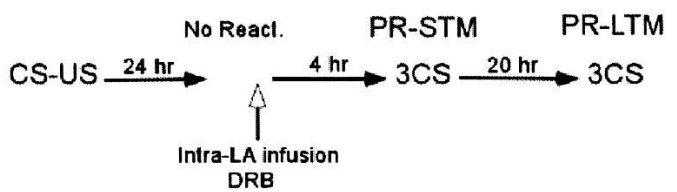

B.

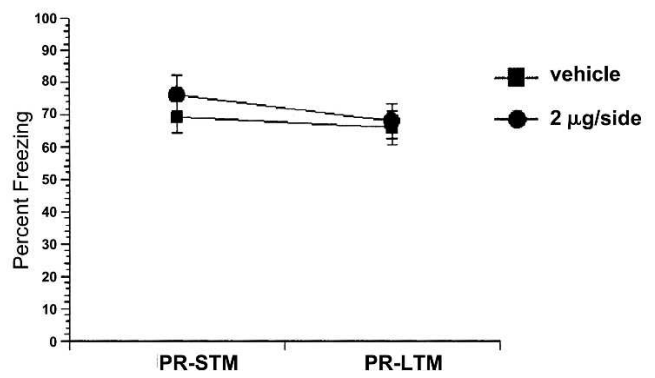

Figure 6. Effect of DRB was dependent on memory reactivation. (A) Schematic of the behavioral procedure used in the experiment. $(B)$ In the absence of reactivation, DRB had no effect on reconsolidation. The DRB rats showed comparable freezing levels to vehicle rats in both tests. The average of three CSs is shown for the freezing scores during PR-STM and PR-LTM. Data represent group means \pm SEM.

expressed the freezing level of each animal during LTM test as a percentage of the average freezing level of the vehicle group. As shown in Figure 7, consolidation and reconsolidation displayed comparable sensitivity to the two drugs across different doses. A two-way ANOVA comparing memory process (consolidation vs. reconsolidation) and drug dose for $\alpha$-Amanitin revealed a main effect of drug dose $\left(F_{(3,39)}=6.24, P<0.05\right)$ as expected but no effect of memory process $(F<1, P>0.05)$ and no significant interaction $(F<1, P>0.05)$ (Fig. 7A). Similar to $\alpha$-Amanitin, a twoway ANOVA comparing memory process (consolidation vs. reconsolidation) and drug dose for DRB revealed a main effect of

A.

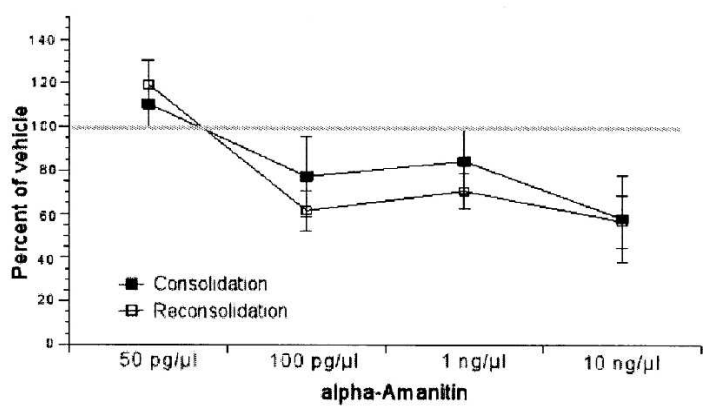

B.

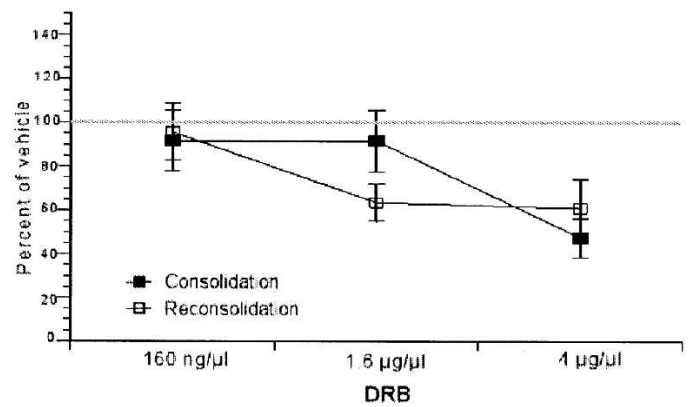

Figure 7. Consolidation and reconsolidation are equally sensitive to disruption of de novo mRNA synthesis. The average of freezing levels of each animal during the LTM test is shown as a percentage of the average freezing level of the vehicle group for each dose of $\alpha$-Amanitin $(A)$ and each dose of DRB $(B)$. 
A.

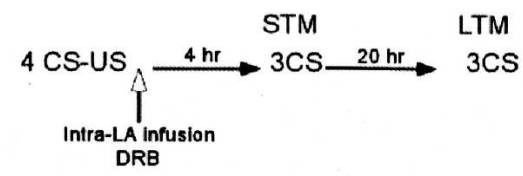

B.

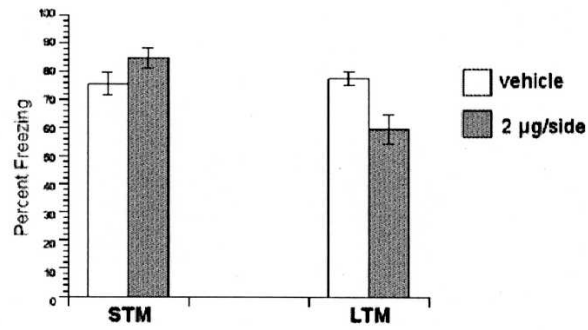

C.
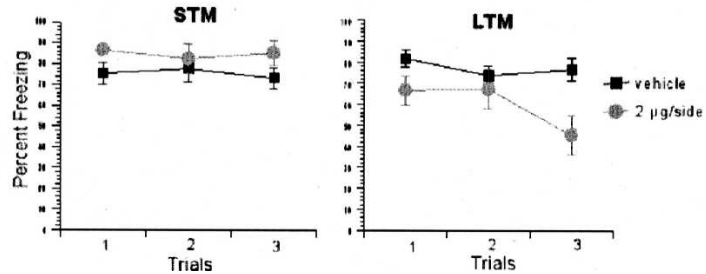

Figure 8. Inhibition of mRNA synthesis in the LA blocked consolidation of multiple-trial auditory fear memories. $(A)$ Schematic of the behavioral procedure used in the experiment. $(B)$ DRB-treated rats showed impairment in the LTM test, but not the STM test. The average of three CSs is shown for the freezing scores during the STM and LTM tests. (C) The freezing scores during each CS of the STM and LTM tests are shown. Data represent group means \pm SEM.

drug dose $\left(F_{(2,29)}=6.31, P<0.05\right)$ but no effect of memory process $(F<1, P>0.05)$ and no significant interaction $(F<1$, $P>0.05$ ) (Fig. 7B). Together these findings suggest that consolidation and reconsolidation are equally sensitive to disruption of de novo mRNA synthesis in the LA.

\section{Do consolidation and reconsolidation of strong fear memories have similar transcriptional requirements?} The previous results showed that consolidation and reconsolidation of one-trial weak fear memories have similar requirements of de novo mRNA synthesis in the LA. It is possible that the molecular mechanisms triggered during memory consolidation and reconsolidation differ depending on the training strength. We therefore sought to test whether transcriptional requirements of multiple-trial learning are similar to that of one-trial learning.

We first tested the requirement of mRNA synthesis during consolidation of multiple-trial fear conditioning (Fig. 8). To this end, we used the dose of DRB that effectively blocked consolidation of one-trial fear conditioning. The rats were conditioned with four pairings of tone CS and footshock US. The conditioning was followed immediately by intra-LBA infusions of DRB (2 $\mu \mathrm{g} /$ side) or vehicle. Consistent with the results of one-trial learning, a repeated-measures ANOVA comparing the effects of treatment (DRB vs. vehicle) over test session (STM vs. LTM) revealed a significant interaction between these variables $\left(F_{(1,9)}=24.9\right.$, $P<0.05$ ) (Fig. 8B). Further post hoc analyses demonstrated that while both groups showed comparable STM scores $(P>0.05)$ (Fig. $8 \mathrm{C})$, they differed significantly during LTM test $(P<0.05)$ (Fig. 8C).

This pattern of results, intact STM and impaired LTM, showed the requirement of de novo mRNA synthesis in the LA for consolidation of multiple-trial fear conditioning. This suggests that both weak and strong training paradigms have similar requirements for mRNA synthesis during consolidation of fear memories in the LA.

To determine the requirement of transcription during reconsolidation of multiple-trial learning, the animals were trained with four pairings of tone CS and footshock US. Twenty-four hours later, they were presented with a single CS to reactivate their memory followed by intra-LBA infusions of DRB ( $2 \mu \mathrm{g} / \mathrm{side})$ or the vehicle (Fig. 9A). During reactivation, both groups showed similar freezing scores. There was no significant difference between the two groups ( $t$-test, $P>0.05)$. Consistent with the results of one-trial learning, a repeated-measures ANOVA comparing drug treatment and test session revealed a significant interaction between these variables $\left(F_{(1,9)}=12.3, P<0.05\right)$ (Fig. 9B). Further post hoc analyses on interaction demonstrated that while both groups showed comparable PR-STM scores $(P>0.05)$, they differed significantly during the PR-LTM test $(P<0.05)$ (Fig. 9C).

This pattern of results, intact PR-STM and impaired PR-LTM, demonstrates the requirement of de novo mRNA synthesis in the LA for reconsolidation of multiple-trial fear conditioning, suggesting that both weak and strong training paradigms have similar requirements for mRNA synthesis during reconsolidation of fear memories in the LA.

\section{Discussion}

Consolidated memories, when reactivated, return to a labile time-dependent state that requires further protein synthesis for restabilization of the memory (Sara 2000; Nader 2003; Dudai 2004; Alberini 2005). Is this time-dependent memory process an

A.

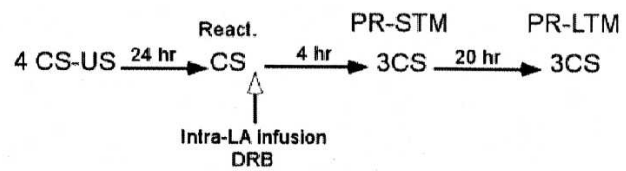

B.

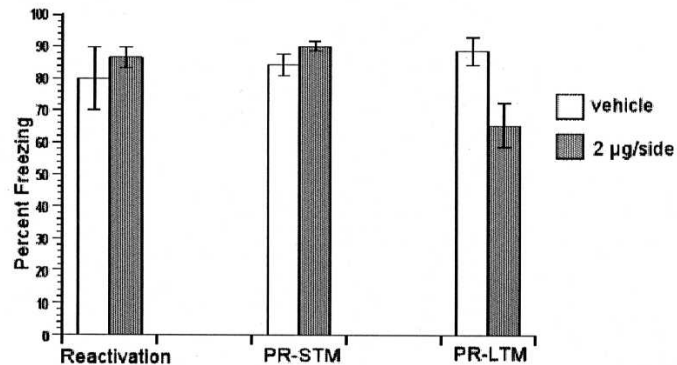

C.
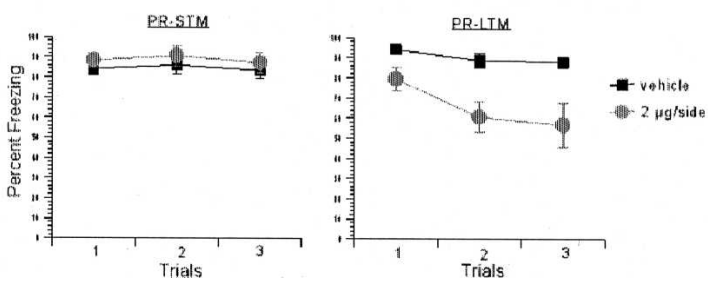

Figure 9. Inhibition of mRNA synthesis in the LA blocked reconsolidation of multiple-trial auditory fear memories. $(A)$ Schematic of the behavioral procedure used in the experiment. $(B)$ DRB treatment impaired PRLTM, but not PR-STM. The average of three CSs is shown for the freezing scores during the PR-STM and PR-LTM tests. (C) The freezing scores during each CS of the PR-STM and PR-LTM are shown. Data represent group means \pm SEM. 
exact recapitulation of the molecular mechanisms underlying consolidation? Given the differences in experimental conditions during consolidation, which is initiated by CS-US pairing, and reconsolidation, initiated by presentation of the CS alone, there could be differences in the molecular mechanisms that underlie these two memory processes. For instance, the temporal requirements for consolidation and reconsolidation have been shown to differ (Gordon and Spear 1973; Mactutus et al. 1979). Some of the differences include the fact that reactivated memories return to a consolidated state faster than consolidation of new memories, and that consolidation and reconsolidation do not always share same dose-response function (Nader 2003). Even small changes in behavioral procedures can alter molecular mechanisms that are engaged. Therefore, in the present study, we tested whether a molecular mechanism, mRNA synthesis, that is required for consolidation of fear memories in the amygdala is also required for reconsolidation.

First, we examined the role of de novo mRNA synthesis in LA during consolidation of auditory fear memories. To this end, we tested the transcriptional requirement of consolidation in the amygdala with two reversible mRNA synthesis inhibitors, DRB and $\alpha$-Amanitin, that work through different mechanisms (Chodosh et al. 1989; Gong et al. 2004). We found that intra-LA infusion of $\alpha$-Amanitin immediately after one-trial learning dosedependently impaired LTM, but not STM. Intra-LA administration of DRB resulted in a similar pattern of findings, verifying $\alpha$-Amanitin's effects. This pattern of results is identical with what has been demonstrated with intra-LA administration of the protein synthesis inhibitor anisomycin (Schafe and LeDoux 2000). Consistent with previous studies (Bailey et al. 1999; Parsons et al. 2006), our results confirmed that de novo mRNA synthesis is necessary for consolidation of fear memories in the amygdala.

Next, we investigated whether reconsolidation of fear memories has similar transcriptional requirements in the LA. To this end, we tested the effects of inhibition of mRNA synthesis in the LA during reconsolidation with the two mRNA synthesis blockers similar to the consolidation experiments. We showed that intra-LA infusion of $\alpha$-Amanitin dose-dependently impaired PR-LTM, but not PR-STM. Furthermore, we demonstrated that this effect of $\alpha$-Amanitin on reconsolidation was contingent on memory reactivation. To verify the results of $\alpha$-Amanitin, we used the second mRNA synthesis inhibitor, DRB, and observed a similar pattern of results, impaired PR-LTM and intact PR-STM. When reactivation was omitted, DRB had no effect. These results demonstrated a requirement for new mRNA synthesis during reconsolidation of single-trial learning.

An important question is whether consolidation and reconsolidation are equally sensitive to blockade of de novo transcription. Our results suggested that, for both $\alpha$-Amanitin and DRB, the effective dose to block reconsolidation might be lower than that needed to block consolidation. To examine this issue in more detail, we directly compared the effect of each dose of the two inhibitors during consolidation and reconsolidation. This analysis showed that consolidation and reconsolidation indeed displayed comparable sensitivity to the two drugs across different doses, suggesting that both memory processes were equally sensitive to blockade of transcription in the LA.

We next asked whether transcriptional requirements of multiple-trial learning are similar to that of one-trial learning. We first tested the requirement of de novo mRNA synthesis during consolidation of multiple-trial fear conditioning. We showed that DRB administration in the LA after a multiple-trial learning resulted in similar findings to that of one-trial learning; namely, an intact STM but impaired LTM. These findings indicate that consolidations of both weak and strong fear memories have similar requirements for mRNA synthesis in the amygdala. However, it is possible that the molecular mechanisms triggered during reconsolidation might be differentially regulated depending on the training strength. To evaluate this, we next tested the effect of mRNA synthesis inhibition during reconsolidation of multiple-trial fear conditioning. Our results showed that intra-LA infusion of DRB impairs PR-LTM, but not PR-STM, similar to its effect on one-trial learning. Taken together, these results demonstrate that both one-trial weak and multiple-trial stronger fear memories have similar transcriptional requirements in LA during reconsolidation.

Many of the molecular mechanisms that are required for consolidation, such as protein synthesis, activation of transcription factors, and signaling cascades, have also been required for reconsolidation (Maren 2001; Schafe et al. 2001a; Nader 2003; Rodrigues et al. 2004; Alberini 2005; Tronson and Taylor 2007). However, there have also been noteworthy differences between the molecular mechanisms underlying consolidation and reconsolidation (Taubenfeld et al. 2001; Debiec and LeDoux 2004; Lee et al. 2004; Tronel et al. 2005; von Hertzen and Giese 2005; Bucherelli et al. 2006). Recently, we have shown that activation of the ERK/MAPK pathway in the LA is required during reconsolidation of auditory fear memories (Duvarci et al. 2005), similar to its requirement during consolidation (Schafe et al. 2001b). In addition to this, a more recent study has shown that the PKA signaling cascade is also required for reconsolidation of auditory fear memories in the amygdala (Tronson et al. 2006), similar to its requirement during consolidation (Schafe and LeDoux 2000). An important role of these signaling cascades is to regulate gene expression. However, they have also been shown to play an important regulatory role at the level of translation. Hence, one important question is whether activation of ERK/MAPK and PKA signaling cascades in the LA during reconsolidation leads to gene transcription. Our results suggest that one role of activation of these signaling cascades during reconsolidation might be regulation of transcription.

The findings of the present study appear to be at odds with a recent study showing that new mRNA synthesis is required for consolidation, but not reconsolidation, of fear memories in the amygdala (Parsons et al. 2006). It is unclear how to reconcile this finding with our own. There are several procedural differences, and it is possible that even subtle changes in experimental procedures can alter molecular mechanisms that are engaged (for review, see Tronson and Taylor 2007). For instance, one obvious difference between the two studies is the duration of CSs used at each session. In the present study, consistent with our previous studies, we used 30 sec-CSs in all the sessions, whereas the Parsons et al. (2006) study used a long single CS (5 min long) during the PR-LTM test while using short CSs during training (10 sec long) and reactivation (32 sec long) sessions. In the present study, animals were habituated to both the training and the testing contexts prior to fear conditioning, whereas the Parsons et al. (2006) study had no habituation session. Another difference between the two studies is the effective dose of DRB that blocked consolidation. Parsons et al. (2006) observed an effect with a much smaller dose of DRB when using a different vehicle. It is possible that the level of dissolvability of the drug is different in different vehicles, possibly explaining why that study had an effect with a smaller dose than in our study. Such procedural differences might account for the differential requirement of de novo mRNA synthesis during reconsolidation in the two studies. For instance, it has previously been shown that reconsolidation depends on expression of only a subset of immediate-early genes required during consolidation (von Hertzen and Giese 2005). It is possible that under some circumstances the existing mRNAs might be sufficient to support reconsolidation. The findings of the Parsons et al. (2006) study, at the least, suggest that recon- 
solidation under some circumstances must be sustained by translation of existing mRNAs. Nevertheless, our results are consistent with previous findings, in other species and other learning paradigms, showing that de novo RNA synthesis is required for reconsolidation (Hall et al. 2001; Kida et al. 2002; Child et al. 2003; Sangha et al. 2003; Lee et al. 2004; Bozon et al. 2003; Merlo et al. 2005; von Hertzen and Giese 2005; Boccia et al. 2007; Lubin and Sweatt 2007; Da Silva et al. 2008).

In conclusion, the findings of the present study provide evidence that consolidation and reconsolidation of fear memories have similar requirements in the LA at the transcriptional level. A requirement for de novo mRNA synthesis indicates that new mRNAs encoding proteins that are not present at the time of memory reactivation must be transcribed for reconsolidation to occur. Thus, de novo mRNA synthesis, like de novo protein synthesis, is required for reconsolidation of fear memories, similar to its requirement in consolidation.

\section{Materials and Methods}

\section{Subjects}

Subjects were adult male Sprague-Dawley rats obtained from Hilltop Labs (Scottsdale, PA). Rats were housed individually in plastic Nalgene cages and maintained on a 12:12-h light/dark cycle. Food and water were provided ad libitum throughout the experiment. All procedures were approved by New York University Animal Care and Use Committee.

\section{Surgery and histology}

Under Nembutal anesthesia $(45 \mathrm{mg} / \mathrm{kg})$, rats were implanted bilaterally with 22-gauge stainless steel cannulas into the lateral amygdala. Coordinates, taken from the method of Paxinos and Watson (1986), were $3.0 \mathrm{~mm}$ posterior to bregma, $5.3 \mathrm{~mm}$ lateral to the midline, and $8.0 \mathrm{~mm}$ ventral to the skull surface. Rats were given at least $7 \mathrm{~d}$ to recover before experimental procedures.

At the end of the behavioral experiment, animals were anesthetized with chloral hydrate $(600 \mathrm{mg} / \mathrm{kg}$ ) and perfused with $10 \%$ buffered formalin. The brains were sectioned and stained using Cresyl violet and examined with light microscopy for cannula penetration into the LBA (Fig. 2).

\section{Drugs}

DRB (Sigma, catalog no. D1916) was dissolved in 100\% DMSO and then diluted 1:1 with artificial cerebrospinal fluid (ACSF) to yield final concentrations of $160 \mathrm{ng} / \mu \mathrm{L}, 1.6 \mu \mathrm{g} / \mu \mathrm{L}$, and $4 \mu \mathrm{g} / \mu \mathrm{L}$ in 50\% DMSO. $\alpha$-Amanitin (Sigma, catalog no. A2263) was dissolved in ACSF to yield final concentrations of $50 \mathrm{pg} / \mu \mathrm{L}, 100$ $\mathrm{pg} / \mu \mathrm{L}, 1 \mathrm{ng} / \mu \mathrm{L}$, and $10 \mathrm{ng} / \mu \mathrm{L}$. In all experiments, drugs were infused slowly via an infusion pump into the LBA at a rate of 0.25 $\mu \mathrm{L} / \mathrm{min}$. Following drug infusion, injectors were left in place for an additional minute to allow diffusion of the drug away from the cannula tip. Although the lateral nucleus was the main target, the $0.5 \mu \mathrm{L}$ infusions probably affected the adjacent basal nucleus. We, therefore, refer to the affected area as the LBA.

\section{Apparatus}

Conditioning and tone testing were conducted in different chambers. For conditioning, rats were placed in a Plexiglas rodent conditioning chamber with a metal grid floor (model E1010, Coulbourn Instruments) that was enclosed within a sound attenuating chamber (model E10-20). The chamber was dimly illuminated by a single house light. For testing, rats were placed in a different Plexiglas chamber (ENV-001, MedAssociates, Inc.). The testing chamber was brightly lit with three house lights and contained a flat black Formica floor that had been washed with peppermint soap. A micro-video camera was mounted at the top of the chamber so that rats could be videotaped during testing.

\section{General behavioral procedures}

In all of the experiments, rats were habituated to the training and testing contexts for $10 \mathrm{~min}$ each on day 1 in a counterbalanced manner. On day 2, the training session consisted of either single (1 CS-US) or multiple (4 CS-US) auditory conditioning trials in which the auditory CS was a $30-\mathrm{sec}$ presentation of a $5-\mathrm{kHz}, 80-$ $\mathrm{dB}$ tone that coterminated with a $1.5 \mathrm{~mA}, 1$-sec foot shock US. In consolidation experiments, STM and LTM were tested 3-4 and 24 $\mathrm{h}$ after training, respectively. In reconsolidation experiments, memory reactivation was performed by presenting a single 30 -sec $\mathrm{CS}$ in the testing context $24 \mathrm{~h}$ after training. Animals were then tested for PR-STM and PR-LTM 3-4 and $24 \mathrm{~h}$ after reactivation, respectively. For all tests, rats received $30-\mathrm{sec}$ presentation of three CSs in the testing context. These time points were chosen based on our earlier studies (Nader et al. 2000; Schafe and LeDoux 2000). In all tests, total seconds of freezing (immobility, with the exception of respiration) (Blanchard and Blanchard 1969) during the CS presentations were scored for each rat, and the scores were shown as the percentage of the total duration of CS presentation.

To control for any nonspecific effects of the drugs and to test whether our findings might have resulted from damage to LBA, we retrained all the animals. At the end of each experiment, rats were returned to their training context and received a single CSUS presentation for retraining. Twenty-four hours after retraining, rats were returned to the testing context and tested with three CS presentations for their retrained LTM. All animals showed normal retraining, and there was no significant difference between the freezing scores of animals during the LTM test of retraining $(P>0.05)$.

\section{Experiment 1}

On the training day, rats were placed in the training context and given a single CS-US trial. Immediately after conditioning, rats were infused with either $\alpha$-Amanitin $(25 \mathrm{pg} / 0.5 \mu \mathrm{L} / \mathrm{side}, n=5 ; 50$ $\mathrm{pg} / 0.5 \mu \mathrm{L} /$ side, $n=6$; $0.5 \mathrm{ng} / 0.5 \mu \mathrm{L} /$ side, $n=7 ; 5 \mathrm{ng} / 0.5 \mu \mathrm{L} / \mathrm{side}$, $n=6)$ or ACSF $(n=6)$. Three to four hours later, rats were given three CS presentations in the testing context as a STM test. Twenty-four hours after conditioning, rats received their LTM test consisting of three CS presentations.

\section{Experiment 2}

The experimental procedure was identical to experiment 1 except that the rats were infused with either DRB $(80 \mathrm{ng} / 0.5 \mu \mathrm{L} / \mathrm{side}$, $n=5 ; 0.8 \mu \mathrm{g} / 0.5 \mu \mathrm{L} /$ side, $n=6 ; 2 \mu \mathrm{g} / 0.5 \mu \mathrm{L} /$ side, $n=7$ ) or vehicle (50\% DMSO; $n=7)$ immediately after conditioning.

\section{Experiment 3}

On day 2, rats were trained with a single CS-US presentation in the training context. The following day, they were placed in the testing context and given a single 30 -sec CS presentation to reactivate their auditory fear memory. Immediately after memory reactivation, rats were infused with either $\alpha$-Amanitin $(25 \mathrm{pg} / 0.5$ $\mu \mathrm{L} / \mathrm{side}, n=4 ; 50 \mathrm{pg} / 0.5 \mu \mathrm{L} / \mathrm{side}, n=6 ; 0.5 \mathrm{ng} / 0.5 \mu \mathrm{L} / \mathrm{side}, n=6$; $5 \mathrm{ng} / 0.5 \mu \mathrm{L} / \mathrm{side}, n=6)$ or ACSF $(n=8)$. Three to four hours later, rats were given three CS presentations in the testing context as a PR-STM test. Twenty-four hours after reactivation, rats received three more CS presentations in the testing context as their PRLTM test.

\section{Experiment 4}

The experimental procedure was identical to experiment 3 except that the tone memory was not reactivated. Rats (ACSF, $n=5$; $\alpha$-Amanitin, $5 \mathrm{ng} / 0.5 \mu \mathrm{L} /$ side, $n=6$ ) were placed in the testing context for the same amount of time it took for reactivation session and then received their infusions.

\section{Experiment 5}

The experimental procedure was identical to experiment 3 except that the rats were infused with either DRB $(80 \mathrm{ng} / 0.5 \mu \mathrm{L} / \mathrm{side}$, 
$n=5 ; 0.8 \mu \mathrm{g} / 0.5 \mu \mathrm{L} /$ side, $n=6 ; 2 \mu \mathrm{g} / 0.5 \mu \mathrm{L} /$ side, $n=6$ ) or vehicle (50\% DMSO; $n=6)$ immediately after memory reactivation.

\section{Experiment 6}

The experimental procedure was identical to experiment 4 except that the rats were infused with either DRB $(2 \mu \mathrm{g} / 0.5 \mu \mathrm{L} / \mathrm{side}$, $n=5$ ) or vehicle (50\% DMSO; $n=7$ ).

\section{Experiment 7}

The experimental procedure was identical to experiment 1 except that the rats received four CS-US trials on the training day. Immediately after conditioning, rats were infused with either DRB $(2 \mu \mathrm{g} / 0.5 \mu \mathrm{l} / \mathrm{side}, n=5)$ or vehicle (50\% DMSO; $n=6)$. Three to four hours later, rats were given three CS presentations in the testing context as a STM test. Twenty-four hours after conditioning, rats received their LTM test consisting of three CS presentations.

\section{Experiment 8}

The experimental procedure was identical to experiment 3 except that the rats received four CS-US trials on the training day. The following day, they were placed in the testing context and given a single 30-sec CS presentation to reactivate their auditory fear memory. Immediately after memory reactivation, rats were infused with either DRB $(2 \mu \mathrm{g} / 0.5 \mu \mathrm{L} /$ side, $n=6)$ or vehicle $(50 \%$ DMSO; $n=5$ ). Three to four hours later, rats were given three CS presentations in the testing context as a PR-STM test. Twentyfour hours after reactivation, rats received three more CS presentations in the testing context as their PR-LTM test.

\section{Statistical analysis}

Statistical analyses were performed using unpaired $t$-test or ANOVAs (one-way, repeated-measures, or two-way) followed by Bonferroni's post hoc $t$-test comparisons at the $P<0.05$ level of significance. Data are presented as group means \pm SEM.

\section{Acknowledgments}

This work was supported by grants to J.E.L. (PHS, NIH grants R37 MH38774, R01 MH46516, P50 MH58911, and K05 MH067048) and to J.E.L. and K.N. (VW I/79 894 and HSF RGP0094/2001-B). K.N. is also funded by NSERC, CIHR, the A.P. Sloan, and EJLB foundations.

\section{References}

Alberini, C.M. 2005. Mechanisms of memory stabilization: Are consolidation and reconsolidation similar or distinct processes? Trends Neurosci. 28: 51-56.

Bailey, D.J., Kim, J.J., Sun, W., Thompson, R.F., and Helmstetter, F.J. 1999. Acquisition of fear conditioning in rats requires the synthesis of mRNA in the amygdala. Behav. Neurosci. 113: 276-282.

Blanchard, R.J. and Blanchard, D.C. 1969. Passive and active reactions to fear-eliciting stimuli. J. Comp. Physiol. Psychol. 68: 129-135.

Boccia, M., Freudenthal, R., Blake, M., de la Fuente, V., Acosta, G., Baratti, C., and Romano, A. 2007. Activation of hippocampal nuclear factor- $\mathrm{B}$ by retrieval is required for memory reconsolidation. J. Neurosci. 27: 13436-13445.

Bozon, B., Davis, S., and Laroche, S. 2003. A requirement for the immediate early gene zif268 in reconsolidation of recognition memory after retrieval. Neuron 40: 695-701.

Bucherelli, C., Baldi, E., Mariottini, C., Passani, M.B., and Blandina, P. 2006. Aversive memory reactivation engages in the amygdala only some neurotransmitters involved in consolidation. Learn. Mem. 13: $426-430$

Child, F.M., Epstein, H.T., Kuzirian, A.M., and Alkon, D.L. 2003. Memory reconsolidation in Hermissenda. Biol. Bull. 205: 218-219.

Chodosh, L.A., Fire, A., Samuels, M., and Sharp, P.A. 1989. 5,6-Dichloro-1- $\beta$-D-ribofuranosylbenzimidazole inhibits transcription elongation by RNA polymerase II in vitro. J. Biol. Chem. 1264: 2250-2257.

Da Silva, W.C., Bonini, J.S., Bevilaqua, L.R., Medina, J.H., Izquierdo, I., and Cammarota, M. 2008. Inhibition of mRNA synthesis in the hippocampus impairs consolidation and reconsolidation of spatial memory. Hippocampus 8: 29-39.
Davis, H.P. and Squire, L.R. 1984. Protein synthesis and memory. A review. Psychol. Bull. 96: 518-559.

Debiec, J. and LeDoux, J.E. 2004. Disruption of reconsolidation but not consolidation of auditory fear conditioning by noradrenergic blockade in the amygdala. Neuroscience 129: 267-272.

Dreyer, C. and Hausen, P. 1978. Inhibition of mammalian RNA polymerase by 5,6-dichlororibofuranosylbenzimidazole (DRB) and DRB triphosphate. Nucleic Acids Res. 5: 3325-3335.

Dudai, Y. 2004. The neurobiology of consolidations, or, how stable is the engram? Annu. Rev. Psychol. 55: 51-86.

Dudai, Y. and Morris, R. 2000. To consolidate or not to consolidate: What are the questions? In Brain, perception, memory. Advances in Cognitive Sciences (ed. J. Bolhius), pp. 149-162. Oxford University Press, Oxford, UK.

Duvarci, S., Nader, K., and LeDoux, J.E. 2005. Activation of extracellular signal-regulated kinase-mitogen-activated protein kinase cascade in the amygdala is required for memory reconsolidation of auditory fear conditioning. Eur. J. Neurosci. 21: 283-289.

Gong, X.Q., Nedialkov, Y.A., and Burton, Z.F. 2004. $\alpha$-Amanitin blocks translocation by human RNA polymerase II. J. Biol. Chem. 279: 27422-27427.

Gordon, W.C. and Spear, N.E. 1973. Effect of reactivation of a previously acquired memory on the interaction between memories in the rat. J. Exp. Psychol. 99: 349-355.

Hall, J., Thomas, K.L., and Everitt, B.J. 2001. Fear memory retrieval induces CREB phosphorylation and Fos expression within the amygdala. Eur. J. Neurosci. 13: 1453-1458.

Kandel, E.R. 2001. The molecular biology of memory storage: A dialogue between genes and synapses. Science 294: 1030-1038.

Kida, S., Josselyn, S.A., de Ortiz, S.P., Kogan, J.H., Chevere, I., Masushige, S., and Silva, A.J. 2002. CREB required for the stability of new and reactivated fear memories. Nat. Neurosci. 5: 348-355.

Lee, J.L., Everitt, B.J., and Thomas, K.L. 2004. Independent cellular processes for hippocampal memory consolidation and reconsolidation. Science 304: 839-843.

Ljungman, M., Zhang, F., Chen, F., Rainbow, A.J., and McKay, B.C. 1999. Inhibition of RNA polymerase II as a trigger for the p53 response. Oncogene 18: 583-592.

Lubin, F.D. and Sweatt, J.D. 2007. The ІкB kinase regulates chromatin structure during reconsolidation of conditioned fear memories. Neuron 55: 942-957.

Mactutus, C.F., Riccio, D.C., and Ferek, J.M. 1979. Retrograde amnesia for old (reactivated) memory: Some anomalous characteristics. Science 204: 1319-1320.

Maren, S. 2001. Neurobiology of Pavlovian fear conditioning. Annu. Rev. Neurosci. 24: 897-931.

Merlo, E., Freudenthal, R., Maldonado, H., and Romano, A. 2005. Activation of the transcription factor NF- $\kappa$ B by retrieval is required for long-term memory reconsolidation. Learn. Mem. 12: 23-29.

McGaugh, J.L. 2000. Memory-a century of consolidation. Science 287: $248-251$.

Nader, K. 2003. Memory traces unbound. Trends Neurosci. 26: 65-72.

Nader, K., Schafe, G.E., and Le Doux, J.E. 2000. Fear memories require protein synthesis in the amygdala for reconsolidation after retrieval. Nature 406: 722-726.

Parsons, R.G., Gafford, G.M., Baruch, D.E., Riedner, B.A., and Helmstetter, F.J. 2006. Long-term stability of fear memory depends on the synthesis of protein but not mRNA in the amygdala. Eur. J. Neurosci. 23: 1853-1859.

Paxinos, G. and Watson, C. 1986. The rat brain in stereotaxic coordinates, 2nd ed. Academic Press, New York.

Rodrigues, S.M., Schafe, G.E., and LeDoux, J.E. 2004. Molecular mechanisms underlying emotional learning and memory in the lateral amygdala. Neuron 44: 75-91.

Sangha, S., Scheibenstock, A., and Lukowiak, K. 2003. Reconsolidation of a long-term memory in Lymnaea requires new protein and RNA synthesis and the soma of right pedal dorsal 1. J. Neurosci. 23: 8034-8040.

Sara, S.J. 2000. Retrieval and reconsolidation: Toward a neurobiology of remembering. Learn. Mem. 7: 73-84.

Schafe, G.E. and LeDoux, J.E. 2000. Memory consolidation of auditory Pavlovian fear conditioning requires protein synthesis and protein kinase A in the amygdala. J. Neurosci. 20: RC96.

Schafe, G.E., Nader, K., Blair, H.T., and LeDoux, J.E. 2001a. Memory consolidation of Pavlovian fear conditioning: A cellular and molecular perspective. Trends Neurosci. 24: 540-546.

Schafe, G.E., Atkins, C.M., Swank, M.W., Bauer, E.P., Sweatt, J.D., and LeDoux, J.E. 2001b. Activation of ERK/MAP kinase in the amygdala is required for memory consolidation of pavlovian fear conditioning. J. Neurosci. 20: $8177-8187$.

Taubenfeld, S.M., Milekic, M.H., Monti, B., and Alberini, C.M. 2001. The consolidation of new but not reactivated memory requires 
hippocampal C/EBPß. Nat. Neurosci. 4: 813-818.

Thut, P.D. and Lindell, T.J. 1974. $\alpha$-Amanitin inhibition of mouse brain form II ribonucleic acid polymerase and passive avoidance retention. Mol. Pharmacol. 10: 146-154.

Tronel, S., Milekic, M.H., and Alberini, C.M. 2005. Linking new information to a reactivated memory requires consolidation and not reconsolidation mechanisms. PLoS Biol. 3: e293.

Tronson, N.C. and Taylor, J.R. 2007. Molecular mechanisms of memory reconsolidation. Nat. Rev. Neurosci. 8: 262-275.
Tronson, N.C., Wiseman, S.L., Olausson, P., and Taylor, J.R. 2006. Bidirectional behavioral plasticity of memory reconsolidation depends on amygdalar protein kinase A. Nat. Neurosci. 9: 167-169.

von Hertzen, L.S. and Giese, K.P. 2005. Memory reconsolidation engages only a subset of immediate-early genes induced during consolidation. J. Neurosci. 25: 1935-1942.

Received April 10, 2008; accepted in revised form July 17, 2008. 


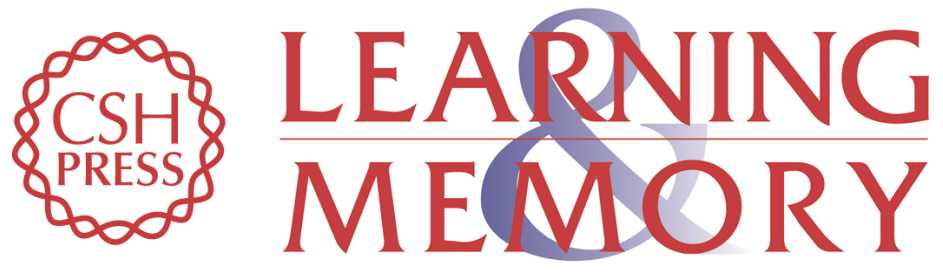

\section{De novo mRNA synthesis is required for both consolidation and reconsolidation of fear memories in the amygdala}

Sevil Duvarci, Karim Nader and Joseph E. LeDoux

Learn. Mem. 2008, 15:

Access the most recent version at doi:10.1101//m.1027208

References This article cites 41 articles, 13 of which can be accessed free at: http://learnmem.cshlp.org/content/15/10/747.full.html\#ref-list-1

License

Email Alerting Receive free email alerts when new articles cite this article - sign up in the box at the Service top right corner of the article or click here. 